\title{
Challenges of using an AUV to find and map hydrothermal vent sites in deep and rugged terrains
}

\author{
Stephen McPhail, Peter Stevenson, Miles Pebody, Maaten Furlong, James Perrett, Tim Lebas. \\ National Oceanography Centre, Southampton, UK.
}

\begin{abstract}
In March 2010, the Autosub6000 AUV embarked on a cruise to discover, locate and map hydrothermal vent sites in an active spreading centre, the Cayman trough in the Caribbean sea. The environment provided the challenge of steep and rugged terrain together with deep water (in places greater than $5000 \mathrm{~m}$ ).

Autosub6000 is a flight class, hydrodynamically shaped AUV, with good endurance capability, making it well suited for searching for plume signals and mapping terrain over the required moderately large areas. However, it must fly at a forward speed greater than $0.8 \mathrm{~ms}^{1}{ }^{1}$ to achieve control, and so it requires a capable forward look collision avoid capability. Another potential challenge is navigation. To make best use of ship time, Autosub6000 missions are commonly conducted with neither the support ship in attendance, nor an acoustic transponder long baseline network. Hence positioning is dependent upon the AUV autonomous navigation (aided by a position fix after the AUV's descent to within ADCP bottom tracking range of the seabed).
\end{abstract}

For the cruise on the UK research ship RRS James Cook, the AUV was equipped with sensors for EH (redox potential), turbidity, CTD, tri axis magnetometer, and an EM2000 multibeam sonar. The paper describes the Autosub6000 vehicle, its systems, capabilities, the missions it undertook in the deep Caribbean sea, and the discoveries it made. The missions, although ultimately very successful, were not without problems, with, for example, the steep seabed slopes, at times affecting the accuracy for the navigation system. The paper will also discuss these issues and how they might be addressed in the future.

\section{INTRODUCTION}

The list of AUVs which have been used to search for hydrothermal vent systems in the deep oceans is short. To date ( the recently sadly lost) ABE AUV [1,2], (succeeded by the SENTRY AUV), had by far the greatest experience and indeed success in finding and mapping deep ocean hydrothermal systems. The $11000 \mathrm{~m}$ rated NEREUS [3] has also recently been used for hydrothermal plume hunting. Indeed, chemical signals detected by this hybrid AUV, in October 2009, during the cruise of the R/V Cape Hatteras to the Mid Cayman Rise, where vitally useful, 4 months later, in defining the initial search area for Autosub6000. The Jaguar SEABED AUV also

This work was funded by the Natural Environment Research Council, UK detected hydrothermal chemical signals during the Arctic Gakkel Vents (AGAVE) Expedition, in July 2007 [4], in difficult and dangerous operating conditions under sea ice.

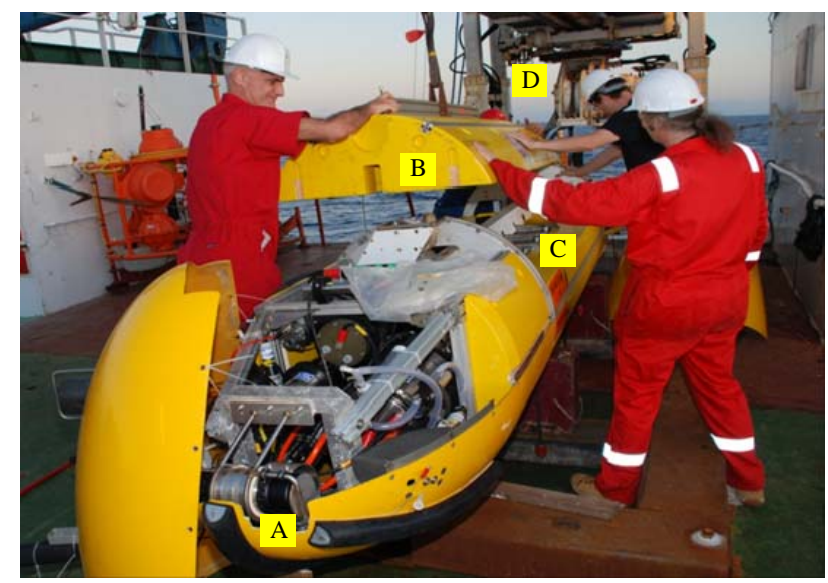

Figure 1. An engineer's view of Autosub6000, as it is readied for its first launch of the Cayman Rise campaign. The front panel is removed revealing the floodable front section, with the majority of the science instruments are housed. The Tritech Seaking (A) sensor used for collision avoidance, lies horizontally across the nose. The upper, syntactic foam centre section (B) is being lowered into place, revealing the 4 pressure tolerant batteries (C). In the background (D) is the dedicated launch and recovery system.

The Autosub6000 operations on RRS James Cook, Cruise 044 to the Mid Cayman Rise, described in this paper, was the first time that the AUV had been used to search for hydrothermal plumes. In fact, it can be argued that it is one the first times that an AUV of this type has been used for such as search (with the possible exception of R2D4 which has detected chemical signals over a lava plain [5]). In two important respects Autosub6000 is quite different to either ABE, NEREUS, SENTRY or JAGUAR: As a flight class AUV Autosub6000 cannot stop, it must maintain speeds of at least $0.8 \mathrm{~ms}^{-1}$ to maintain forward control. Secondly, the navigation mode for Autosub6000 is almost fully autonomous (except for initial positioning at the start of the mission, following descent to the seabed), as it does not rely on LBL acoustic net nor ship support via USBL for its navigation. Both these design features have impacts, positive and negative, 
upon the ease and effectiveness of hydrothermal plume searches.

This paper describes the technical issues of use of a flight class, autonomously navigated AUV such as Autosub6000 for hydrothermal plume hunting, through the description of the RRS James Cook cruise 44 (JC044), Cayman Rise expedition of March 2010, the problems encountered, and how these might tackled in the future similar missions.

TABLE I

SPECIFICATION OF THE AUTOSUB6000 AUV FOR JC044 (MARCH 2010)

\begin{tabular}{|c|c|}
\hline Size & $5.5 \mathrm{~m}$ long, $0.9 \mathrm{~m}$ Diameter \\
\hline Mass & 1800 kg (dry mass). 2900 kg (flooded). \\
\hline $\begin{array}{l}\text { Endurance } \\
\text { Range }\end{array}$ & $\begin{array}{l}\text { a } 27 \text { hours, } 155 \mathrm{~km} \text { at } 1.6 \mathrm{~ms}-1 \text {. Up to } 2 \mathrm{x} \text { this possible with } \\
\text { available battery payload space. }\end{array}$ \\
\hline Speed & 0.8 to $1.8 \mathrm{~ms}^{-1}$. \\
\hline $\begin{array}{c}\text { Descent / } \\
\text { Ascent Rates }\end{array}$ & $-1.0 \mathrm{~ms}^{-1} / 1.5 \mathrm{~ms}^{-1}$ \\
\hline $\begin{array}{l}\text { Maximum } \\
\text { Depth }\end{array}$ & $6000 \mathrm{~m}$ (currently tested to $5600 \mathrm{~m}$ ). \\
\hline Navigation & $\begin{array}{l}\text { GPS on surface } \\
\text { b0.1\% of distance travelled when within } 200 \mathrm{~m} \text { of the } \\
\text { seabed, using the IXSEA PHINS and } 300 \mathrm{kHz} \text { RDI } \\
\text { Teledyne Workhorse Navigator ADCP }\end{array}$ \\
\hline Flight modes & Constant depth or altitude, Profiling between set depths. \\
\hline $\begin{array}{l}\text { Collision } \\
\text { Avoidance }\end{array}$ & $\begin{array}{l}\text { Forward look obstacle avoidance based on Tritech Seaking } \\
\text { scanning sonar, with turn retry algorithm. }\end{array}$ \\
\hline $\begin{array}{l}\text { Relocation - } \\
\text { surface }\end{array}$ & $\begin{array}{l}2 \text { independent ARGOS satellite tracking beacons. } 2 \\
\text { independent Novatech ST-400 A Flashing lights. }\end{array}$ \\
\hline Coms - surface & $\begin{array}{l}\text { WiFi (IEEE } 802.11 \mathrm{~g} \text { ) with range of } 1 \mathrm{~km} \text {. All data can be } \\
\text { downloaded via this link, and new missions can be } \\
\text { uploaded. }\end{array}$ \\
\hline $\begin{array}{l}\text { Coms - } \\
\text { underwater }\end{array}$ & $\begin{array}{l}\text { LinkQuest Tracklink } 1000 \text { for USBL and two way short } \\
\text { messages of vehicle parameters up to } 7 \mathrm{~km} \text { range. }\end{array}$ \\
\hline $\begin{array}{l}\text { Battery } \\
\text { Recharge }\end{array}$ & 8 hours \\
\hline Payload Space & $0.5 \mathrm{~m}^{3}$ in the free flooded nose section of the vehicle. \\
\hline $\begin{array}{l}\text { Current Sensor } \\
\quad \text { Suite }\end{array}$ & $\begin{array}{l}\text { EM2000 Multibeam Sonar. Seabird } 911 \text { dual CTD system } \\
\text { with DO, LSS, and }{ }^{C} \text { EH sensor. Workhorse } 300 \mathrm{kHz} \\
\text { ADCP Navigator with Current Profiling. Tri axis flux gate } \\
\text { magnetometer (Applied Physics Inc., model 1540). } \\
{ }^{\mathrm{d}} \text { Survey Photographic System. } 1 \mathrm{~km}^{2} \text { per day, at } 10 \mathrm{~mm} \\
\text { resolution (mono). }\end{array}$ \\
\hline Transport & $\begin{array}{l}2 \text { x20 foot ISO shipping container for the AUV and } \\
\text { Launch and Recovery system. }\end{array}$ \\
\hline \multicolumn{2}{|c|}{$\begin{array}{l}\text { a Space for up to } 3 \times \text { this capacity of batteries } \\
\text { b Rough terrain and high pitch angles significantly degrade the accuracy. } \\
\text { 'Courtesy of Ko-ichi Nakamura, National Institute of Advanced Industrial } \\
\text { Science and Technology, Japan. } \\
{ }^{\mathrm{d}} \text { System is experimental. }\end{array}$} \\
\hline
\end{tabular}

\section{The Autosub6000 AUV}

Autosub6000 had its first sea trials 2007, with its first science mission in 2008, investigating, using multibeam sonar, deep scour features in water depths of around $4000 \mathrm{~m}$ in the West North African and European margins [6]. Further technical trials in October 2009 followed, aimed particularly at developing and testing the recently installed collision avoidance system [7], and testing the sensors and systems for the forthcoming cruise to the mid Cayman Rise. Table 1 summarises the current features and capabilities of the AUV. Perhaps more interesting from an engineers perspective is the photograph of Autosub6000 with its cover removed (Fig. 1) showing some of the features of the AUV designed to help cope with working in rugged terrains, from the prosaic (the fenders at the front of the AUV designed to protect the AUV in the event of a seabed collision), to the somewhat more sophisticated Tritech scanning sonar system used for the collision avoidance system. Also visible are the pressure tolerant batteries, mounted in the AUV centre section within slots built into the syntactic foam.

\section{A) Collision Avoidance}

The obstacle avoidance system is its described in some detail in [7], but it worthwhile to describe the salient features here, as its was very important in providing the confidence to carry out the missions of JC044.

As a flight class AUV, Autosub6000 is unable to stop and assess the situation when an obstacle ahead is encountered. It must both react in time to avoid collision as it travels forward, and must also remain in areas where it has enough space to manoeuvre, without risk of collision due it's limited pitch and turning flight envelope. The requirement for the system was also constrained in that it must as far as possible retrofit onto the existing (well tested) depth and altitude control system. Further, it is desirable that the AUV continues on its preprogrammed track as much as possible, hence the avoidance behaviour should be mostly in the vertical plane. The solution was to integrate a mechanically scanned sonar system onto the vehicle, which unlike its normally used mode for ROV operation (horizontal scan), is used to scan , ahead on the vehicle in the vertical plane at $+/$ - 45 degrees to the vehicle pitch axis. The key to the sensing algorithm, is that the system scans for, and locks onto the horizon, i.e. the transition between the area where sonar returns are obtained (from the seabed), and where no sonar returns are returned (above the seabed). The angle of elevation and range to this horizon, is the pertinent information that the depth control system needs for avoiding collision with the seabed. Put simply, if the horizon position is shallower than the current depth, the AUV must immediately pull up. The system fits very simply into the existing control architecture by arranging that its output data is a pseudo altitude which is used by the altitude control algorithm in the same ay as would be an altitude measured by a downward looking sonar. Unlike a normal altitude, this pseudo altitude can take on a negative value, meaning that the horizon is shallower than the AUV current depth. In such a situation the AUV pulls up sharply. The forward looking sonar system has a range of approximately $150 \mathrm{~m}$ (depending upon the seabed type and grazing angle). If the system detects that a cliff ahead cannot be negotiated (due to limited maximum pitch ), then the AUV will execute an algorithm to turn around, back track and try again at a shallower depth.

Without doubt there are limitations with this type of approach, and ultimately the performance of the AUV will be 
limited by its manoeuvrability. In some environments, it will not be possible for the AUV to operate as close to the seabed as desired. However, the system is designed such that the AUV can at least be operated in areas with rugged terrain with some confidence. The system tends to be conservative, in the sense that it prevents the AUV descending into dangerous hollows.

\section{B) Navigation}

Perhaps a distinguishing characteristic of the Autosub series of AUVs is that they have tended to be operated in unescorted missions, where the mother ship either carries out other operations after the AUV has been deployed, e.g. [6] or that it is physically impossible for the mother ship to escort the AUV, as in the sub ice-shelf operations of Autosub3 [8]. Hence the AUV has never used LBL or USBL systems for positioning during the execution of missions (although Range-Only positioning is used to position the AUV post its descent to the seabed mission [9]). Instead, the AUV relies on dead reckoning, using the IXSEA PHINS fibre optic gyro based inertial navigation system (INS) providing accurate attitude (including heading) data, with an RDI Teledyne $300 \mathrm{kHz}$ ADCP providing accurate ground velocity when the AUV is within $200 \mathrm{~m}$ of the seabed. In the past, accuracies of the order of $0.1 \%$ of distance travelled have been achieved with this type of navigation system, and potentially better than that when the missions are area coverage, rather than straight line, such that the radial distance moved is not large. However, the reliance on dead reckoning and, more particularly, the limit of $200 \mathrm{~m}$ for bottom tracking which was recognised as a is a potential limitation for wide vent hunting missions, because there is a greater chance of intercepting a hydrothermal plume when it has mixed and cooled sufficiently, such that it becomes neutrally buoyant, and spreads out over a wider area. For the Autosub6000 missions to the Mid Cayman Rise in 2010, it was interesting to note whether this would, in practice, be a serious limitation.

\section{JC044 to the Caribbean Sea}

\section{A) Background}

The main objective of the James Cool Cruise 044 to the Mid Cayman Rise was simple: to locate and confirm the position of hydrothermal vent sites, for later (on a separate cruise) detailed investigation by an Remotely Operated Vehicle, ISIS. Other platforms used on the cruise were : TOBI (Towed Ocean Bottom Instrument) identifying geological features through sidescan backscatter imagery; EM12 ship based multibeam sonar (with a resolution of the order of $100 \mathrm{~m}$ in the typical depths); Ship base CTD, EH and Turbidity sensors and the HyBIS ROTV (remotely-operated tethered vehicle), video grab system. However, the main tool for locating the position of the vents, was Autosub6000, with HyBIS later used to confirm the positions of the vent sites using its video system. The work was greatly assisted by the surveys and signals detected in October 2009, during the cruise of the R/V Cape Hatteras, by the WHOI NEREUS hybrid ROV/AUV and the ship's CTD.
Fig. 2 is a map (based on ship collected multibeam bathymetry), of the Mid Cayman Rise (MCR), an ultra slow spreading centre, at the boundary of the Caribbean and North American tectonic plates. The $R / V$ Cape Hatteras cruise data directed us to 4 main areas, marked A (a deep valley area to the north), B + C (over and the flanks of Mount Dent), D (in the southern valley). The areas surveyed by Autosub6000 are marked in red. Vents were eventually discovered in areas A and $\mathrm{B}$.

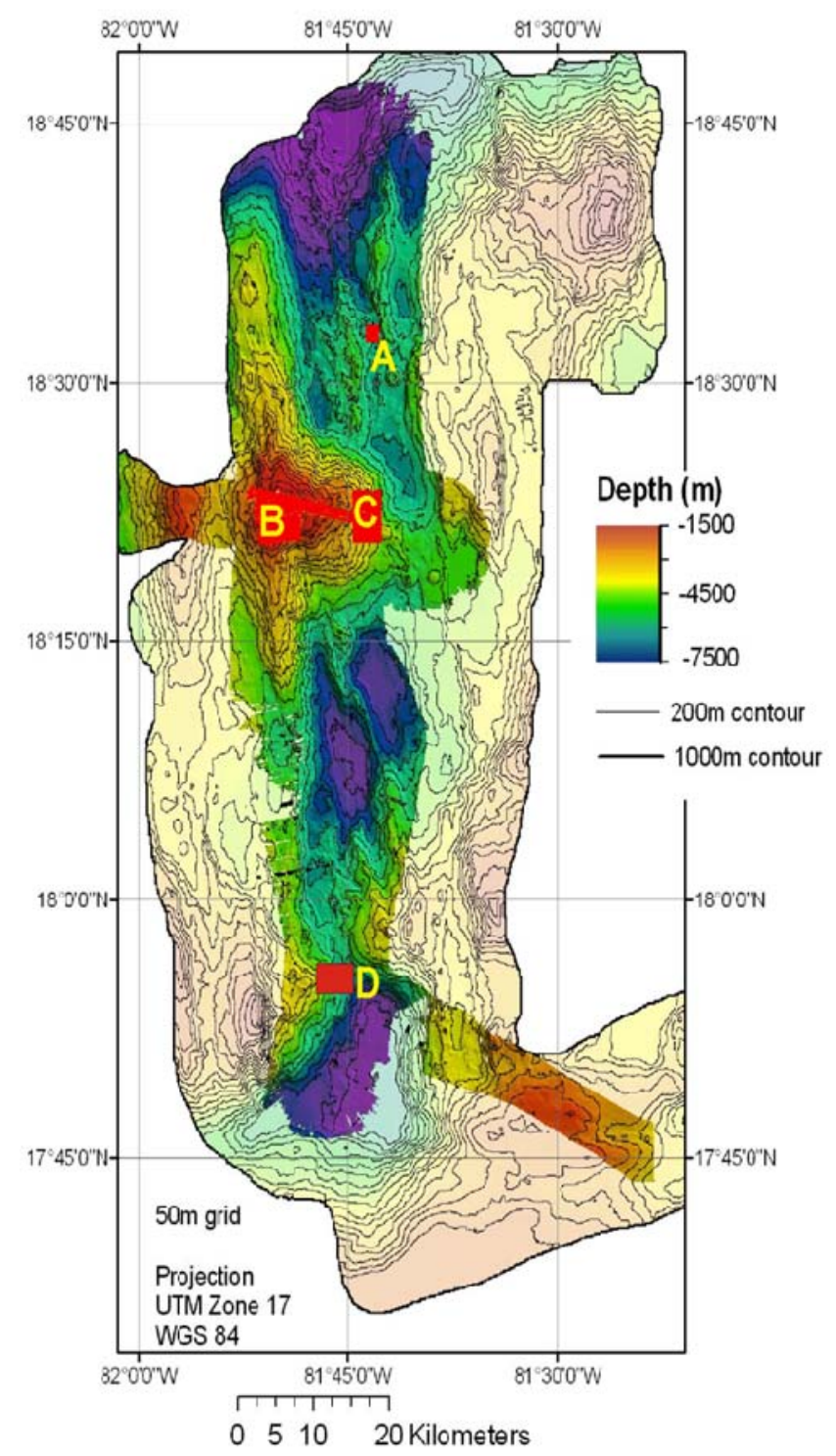

Figure 2. The general area of the mid Cayman Rise spreading centre. The deeply coloured area is that surveyed during the cruise with ship based (EM12 ) multibeam. The AUV survey areas are marked in red. Hydrothermal plumes were found in areas A and B. Area C was surveyed for geology, and area D was eliminated as a potential vent area by an AUV profiling survey. 


\section{B) Autosub6000 Missions}

There were existing data indicating the presence of a hydrothermal vent site from the September 2009, R/V Cape Hatteras CTD Tow-Yo and NEREUS AUV dives, but the exact position was unknown, and attempts to find the site with NEREUS had failed, with bad weather curtailing the operations.

From the NEREUS data, we knew the position of the vent source within a $1 \mathrm{~km}^{2}$, box, and perhaps rather optimistically (as it later turned out) we decided to program Autosub6000 with $17 \mathrm{~m}$ line spacing survey, at an altitude of $40 \mathrm{~m}$, over a box area of $1.5 \mathrm{~km}^{2}$. The lines were east to west, and the progression was from the south to the north. Information for this and the other Autosub6000 missions are listed in Table II.

\section{TABLE II.}

TABLE2. THE SUMMARY DETAILS FOR EACH OF THE MISSIONS. A MISSION NUMBER B: AREA (FIG. 1), C: MISSION DURATION (HRS), D: AREA SURVEYED $\left(\mathrm{KM}^{2}\right)$, E: LINE SPACING (M), F: SURVEY ALTITUDE (M), G: N/S EXTENT OF DETECTABLE PLUME (M).

\begin{tabular}{|c|c|c|c|c|c|c|c|}
\hline A & B & C & D & E & F & G & Notes \\
\hline 28 & A & 27 & 1.5 & $17^{\mathrm{a}}$ & 40 & 500 & $\begin{array}{l}\text { Multibeam and EH survey at northern } \\
\text { vent site. }\end{array}$ \\
\hline 29 & A & 23 & 3.7 & 40 & 60 & 300 & $\begin{array}{l}\text { Multibeam and EH survey of the } \\
\text { northern vent site. }\end{array}$ \\
\hline 30 & B & 24 & 17 & 200 & 100 & $500^{\mathrm{b}}$ & $\begin{array}{l}\text { Multibeam and EH survey of the } \\
\text { southern top flank of Mnt. Dent. }\end{array}$ \\
\hline 31 & $\mathrm{D}$ & 24 & 3.5 & 50 & 100 & 0 & $\begin{array}{l}\text { Multibeam and EH survey of southern } \\
\text { potential vent site. }\end{array}$ \\
\hline 32 & $\mathrm{D}$ & 19 & 15 & $250^{c}$ & NA & 0 & $\begin{array}{l}\text { Profiling mission between } 4200-4400 \\
\& 4600-4800 \mathrm{~m} \text {. }\end{array}$ \\
\hline 33 & B & 22 & 18 & 250 & 100 & 250 & $\begin{array}{l}\text { Multibeam and EH survey over flank } \\
\text { of Mnt. Dent. }\end{array}$ \\
\hline 34 & B & 22 & 4 & 70 & 60 & 630 & $\begin{array}{l}\text { Detailed Multibeam and EH survey } \\
\text { over top of Mnt. Dent }\end{array}$ \\
\hline 35 & C & 25 & 20 & 250 & 100 & 0 & $\begin{array}{l}\text { Multibeam mission on lower eastern } \\
\text { slopes of Mnt Dent. }\end{array}$ \\
\hline 36 & B & 19 & 14 & 250 & 100 & 700 & $\begin{array}{l}\text { Fill-in Multibeam survey areas, } \\
\text { summit of Mnt. Dent. }\end{array}$ \\
\hline
\end{tabular}

\footnotetext{
a Following significant navigation bias early in the mission, manual intervention in the last third of mission set the line spacing at $100 \mathrm{~m}$.

${ }^{\mathrm{b}}$ Signal was detected at the edge of the survey area.

c Poor Navigation as expected because the AUV was mostly beyond ADCP bottom track range.
}

The significant problem which occurred during this mission was the AUV self navigation. For the first half of the mission, the ship carried out other work (CTD stations) within the general area, but beyond accurate reach of the USBL tracking system. When we returned to the survey area, we discovered that the AUV had not progressed as far along its survey as planned. In fact, the actual average line spacing, was $7 \mathrm{~m}$ rather than the planned $17 \mathrm{~m}$, representing a navigation drift of $10 \mathrm{~m}$ south for each pair of reciprocal lines. Over the $2.6 \mathrm{~km}$ total distance of the reciprocal line pairs, this represents a navigation drift rate of $0.4 \%$ of the distance travelled, or $5 \mathrm{~mm}$ per second to the south. A factor of 4 worse than we expected.

The cause of this navigation error is still being investigated, the detailed analysis not being appropriate for this paper, but a number of points can be made: At first, this systematic drift south caused some perplexity. Normally, we would consider that navigation biases due to measurements of velocity in the AUV frame of measurement cancel out over reciprocal runs. For example, it the AUV tends to track to port by 1 degree heading west to east (e.g. due to a misalignment between the ADCP and the INS system), the same bias, when heading east to west would cancel the positional error. However, Fig. 3, might point to an explanation of how a AUV navigation frame error could be resolved into a consistent navigation bias in the geographical frame of reference. There were a number of contributing factors. The terrain was consistently, over the east to west track lines, moderately steep, with an average slope of 7 degrees, and peak slopes of 45 degrees. The AUV does not have active buoyancy control, and tends to gain buoyancy at depth (at $5000 \mathrm{~m}$, this was deepest survey mission it had ever carried out). Its buoyancy during the mission is estimated at 25 $\mathrm{kg}$. To achieve long mission times, the AUV was run a low power, with a planned average speed of $1.4 \mathrm{~ms}^{-1}$. The result of this was that the AUV significantly slowed down when doing work against its buoyancy, heading downhill, and speeding up on the return leg. The consequence of this was that the west to east legs took 350 seconds longer than the west to east legs. A consistent bias in the AUV frame velocity measurement (either due to an ADCP, INS or software problem) would be resolved by this time difference as a navigation bias. For example a constant $28 \mathrm{~mm} \mathrm{~s}^{-1}$ bias to starboard, for whatever reason, would cause the resultant error in navigation.

The scientific usefulness of the first mission was rescued when on returning within USBL tracking range, we noticed the navigation bias, with only $25 \%$ of the mission time remaining. At the end each reciprocal run, we acoustic telemetered to the AUV a position offset to the north, forcing the AUV to effectively increase its line spacing from (a planned) $17 \mathrm{~m}$, to $100 \mathrm{~m}$. By this means we were able to ensure that the AUV covered the target area, and as the later analysis of the $\mathrm{EH}$ showed, the hydrothermal source was passed 5 times, pin pointing its position to better than $100 \mathrm{~m}$ error.

High resolution multibeam was collected during this mission, and it is interesting to note that by comparing this data with the ship collected multibeam data (a manual process), it was a relatively simple matter to correct for the gross navigation errors. This points to possible future navigation approaches and improvements, which are discussed further in the conclusion of this paper. The resulting navigation accuracy was sufficient, such that an hour after recovering the data from Autosub6000, the HyBIS deep video grab system was lowered to the seafloor, and within an hour of it reaching the seafloor, it was videoing the geology and fauna at the world's deepest discovered hydrothermal vent at $4960 \mathrm{~m}$. 
It is interesting to consider the performance of the collision avoidance system for this mission. Fig. 4 is a plot of the AUV altitude, depth, and the water depth for the same track pairs as Fig. 3. The collision avoidance system, uses a horizon tracking algorithm with a Seaking scanning sonar system as the sensor. The system as a whole was designed to be easily retrofitted onto the AUV existing control system, hence the concept of a pseudo altitude, which this system outputs, compared to the altitude, which is derived from the average of the ADCP four range measurements (corrected for geometry). The control system uses the lower value of pseudo altitude and altitude.

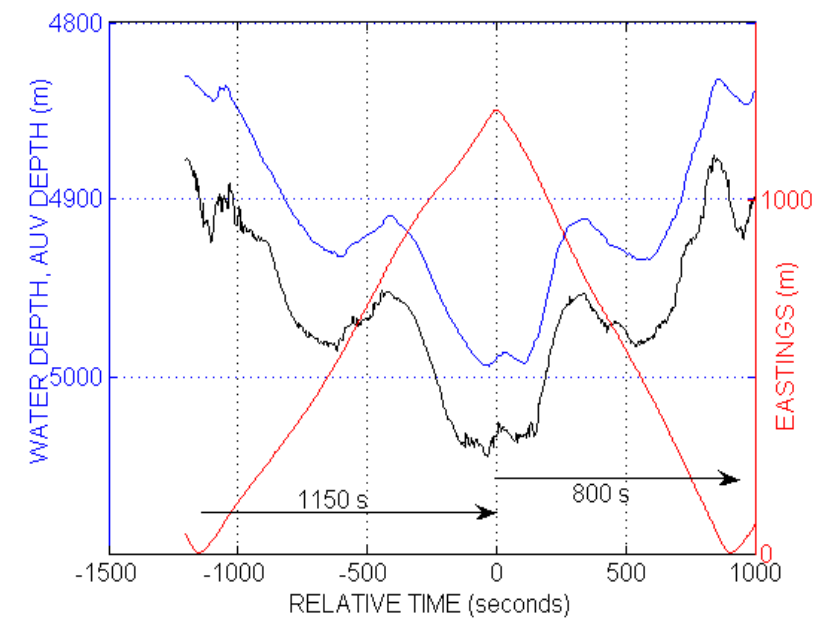

Figure 3. The water depth, AUV depth and eastings vs time for an east/west and west/east track during mission 28. The 'downhill' tracks (heading east) were significantly slower than the 'uphill' (heading west). This disparity is thought to be related to the navigation issues for this mission.

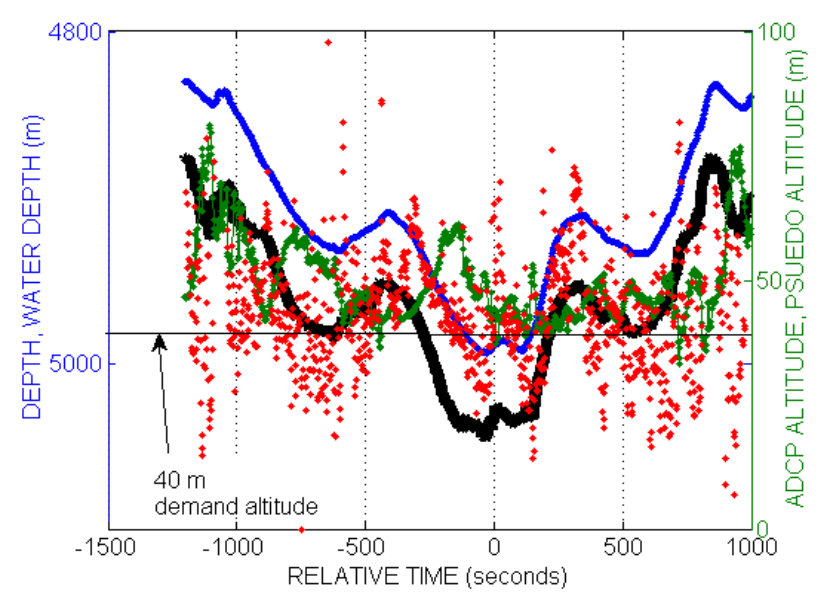

Figure 4. Behaviour of the collision avoidance system. East then west tracks for two lines of Mission 28 (same position as Fig. 3). Black is the water depth, blue the AUV depth. The depth control system uses the lower value of either the pseudo altitude (produced by the scanning sonar based collision avoidance system), and the ADCP altitude, for the feedback control. At times (where the AUV approaches a steep slope), the pseudo altitude is significantly less than the demand altitude, causing the AUV to pull up.
The demand altitude was $40 \mathrm{~m}$, and in parts of the track there are steep slopes of up to 45 degrees and more. These slopes would potentially be dangerous without the facility of a forward looking the collision avoidance system. At times, where there were approaching steep slopes the pseudo altitude drops well below the $40 \mathrm{~m}$ demand altitude. This causes the AUV to pitch upwards, earlier, hence reducing the risk of collision. The system requires more analysis and tuning, as there is evidence for limit cycle behaviour as the forward looking sonar acquires and then looses the seafloor returns as it pitches up. Hence the system was effective, but could be improved.

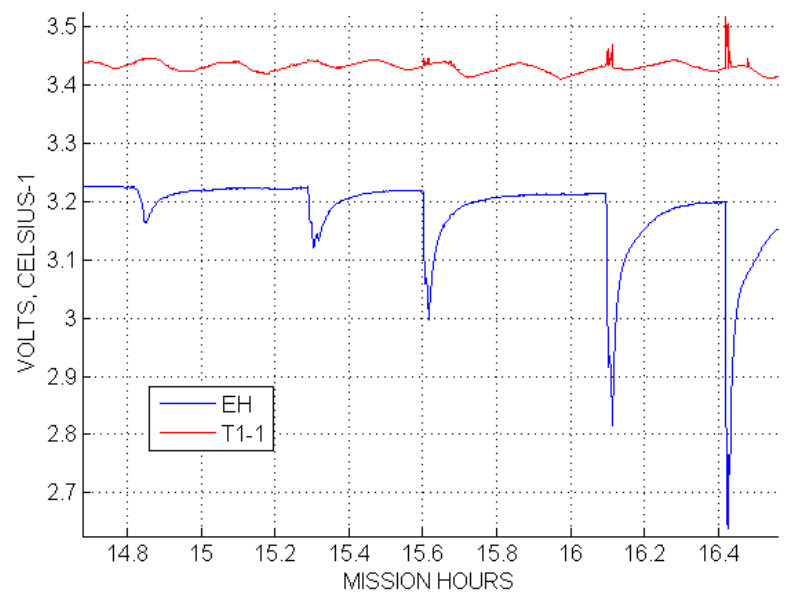

Figure 5. Time Series EH and temperature signals for Mission 29 The AUV was executing East $\rightarrow$ West (and reciprocal) tracks, and progressing southwards. The abrupt cessation of the signals after the last, and strongest signal suggests a north heading current. EH signal was detectable on 5 lines, temperature spikes (up to 0.1 Celsius) on 2. LSS (backscatter) signals were also detected on the two last lines.

Quickly following this success, Autosub6000 was launched again, carrying out a $3.7 \mathrm{~km}^{2}$ survey of the same general area, at $60 \mathrm{~m}$ altitude, collecting high resolution multibeam, as well as the physical and chemical measurements. Navigation problems were still encountered for this mission (hence, a theory tested and disproved, that it was the excessive static roll of the vehicle of -6 degrees, which was contributing to the problems), but the increased line spacing meant that the navigation drift was much less of a problem, and the resulting navigation was easily corrected using the multibeam data. Fig. 5 is a time series of the redox potential measurement (blue) and the temperature (from one of the Seabird 911 dual sensors). Note the clear, and characteristic fast (few seconds) onset and slow (several minutes) recovery of the $\mathrm{EH}$ sensor, and the efficiency that this sensor had for detecting the plumes, with signals detected over 5 passes, whereas there was a small temperature spike (maximum 0.1 Celsius) over three of the passes. The EH signal increased as the AUV lines moved south, and then abruptly stopped, suggesting the source is in 
the south and the current is northerly (the HyBIS deployment confirmed this).

The method of surveying using reciprocal "lawnmower" type tracking, is quite complimentary to the $\mathrm{EH}$ sensor response, as the fast onset response of the sensor, can be used to define the extents (in the case, in longitude), or the plume, as the plume is passed heading east to west and then west to east. Fig. 6 is a plot of the high passed (with respect to time) filtered $\mathrm{EH}$ signal (the time constant is 30 seconds). Use of the high passed signal allows the data to be examined quickly as a $2 \mathrm{D}$ scatter plot, with any slow variation of the sensor output (e.g. due to temperature and pressure changes) effectively eliminated. This approach is a crude approximation of a matched filter for this sensor data. Using this processing it is quite easy to discern the detected extents of the plume, in this case $300 \mathrm{~m}$ north/south, and $260 \mathrm{~m}$, east/west.

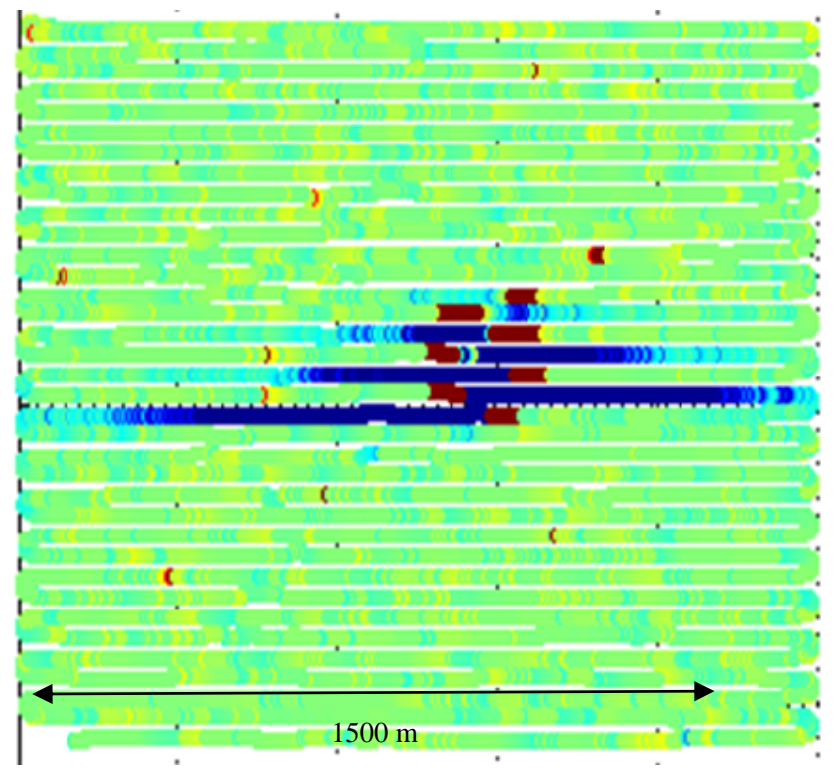

Figure 6. High pass filtered (30 second time constant), reduction- oxidation potential (EH) for Mission 29. Colour range adjusted manually for maximum visual detection of the signal ( $-5 \mathrm{mV}$ (red) is full scale). The sharp onsets (red) for the E/W and W/E lines define the extent of the plume. The plume is $300 \mathrm{~m}(\mathrm{~N} / \mathrm{S}) \times 260 \mathrm{~m}(\mathrm{E} / \mathrm{W})$ in extent, at the AUV flying height of $60 \mathrm{~m}$.

A tri-axis flux gate magnetometer was installed on the AUV. Fig. 7 is a plot of the normalised total field. The quality of this data as critically dependent upon a calibration procedure which the AUV executed (at the end of each mission), involving circling and pitching as steeply as possible in mid water while collecting data for 10 minutes (such a procedure is easy to program for an AUV - more difficult for an ROV or towed vehicle - another practical advantage of using an AUV). The calibration software (Author Alain Barraud, Suzanne Lesecq, CNRS, France) involves fitting the three axis data to an ellipsoid function.

Mission 30 was at site ' $\mathrm{B}$ ', over the south west flanks of Mount Dent, the positioning again guided by signals seen on the $R / V$ Cape Hatteras cruise in 2009. No signals were detected in the areas indicated by the R/VCape Hatteras cruise, but there was however, a weak EH signal detected at the north east edge of the survey area. At the time there was some doubt as to whether the signal was due to a vent, or an artefact, as it coincided with the turning and depth changing of the AUV. A subsequent HyBIS dive near the area found nothing of interest, and so it was decided to leave this area and to use Autosub6000 to thoroughly survey a position in the south of the study area (area ' $D$ '), where small light back scatter signals had been previously detected. These surveys (missions 31 and 32) detected no signals. It was thought that perhaps the signals detected on the R/V Cape Hatteras cruise had been due to resuspended sediment. Mission 32 was interesting in that it was a profiling (or 'Yo-Yo') mission over a box Area, carried out at first at 4200 to $4400 \mathrm{~m}$, and then $4600 \mathrm{~m}$ to $4800 \mathrm{~m}$. During this mission the AUV was beyond ADCP bottom track range, and hence the navigation was severely affected by the current. Autosub6000, as configured, is perhaps not the best tool for this type of mission.

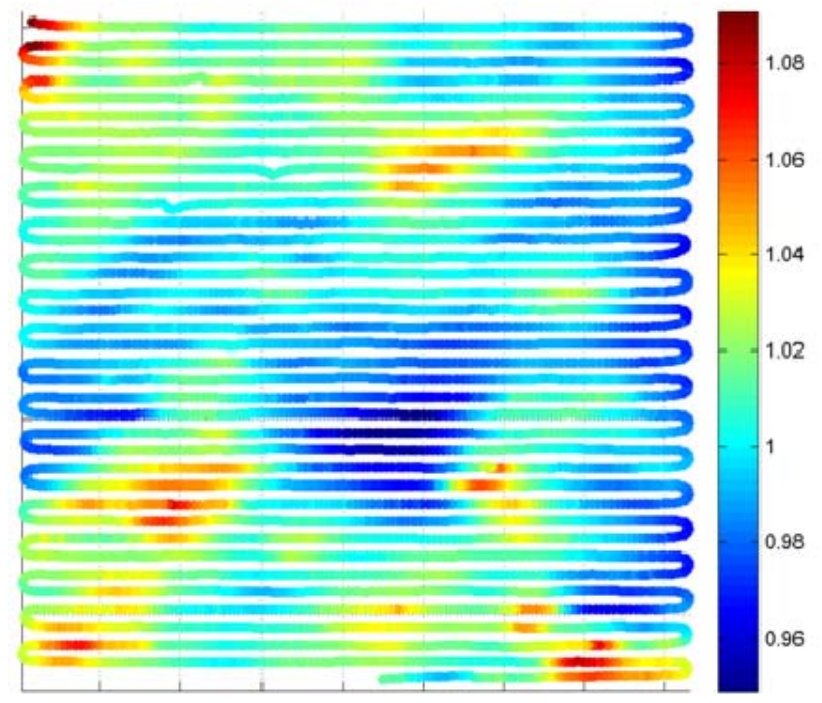

Figure 7. Normalised total field of the tri axis magnetometer (mean value of $\left(\mathrm{Mx}^{2}+\mathrm{My}^{2}+\mathrm{Mz}^{2}\right)^{0.5}$ is 1.0) for the first vent site A. Side is $1.7 \mathrm{~km}$. The calibration Matlab code was authored by Alain Barraud and Suzzane Lesecq, CNRS, France.

Mission 33 returned to Mount Dent, with a $18 \mathrm{~km}^{2}$ survey east/west over the summit, close to where the small signal had been detected on mission 30. This revealed a significant EH spike, on one line, with a weaker signal on a second, and the high resolution multibeam data detecting, close by, a $30 \mathrm{~m}$ wide mound, a plausible vent site ( Fig. 8). Following this, Autosub6000 carried out a higher resolution survey, centred on this signal (mission 34). This confirmed the mound as the source, detecting a 0.45 Celsius temperature increase, coincident with an EH spike. The AUV must have passed quite close to the vent. Immediately after the Autosub6000 recovery, HyBIS was deployed to confirm and video the site, at a depth of $2300 \mathrm{~m}$. 


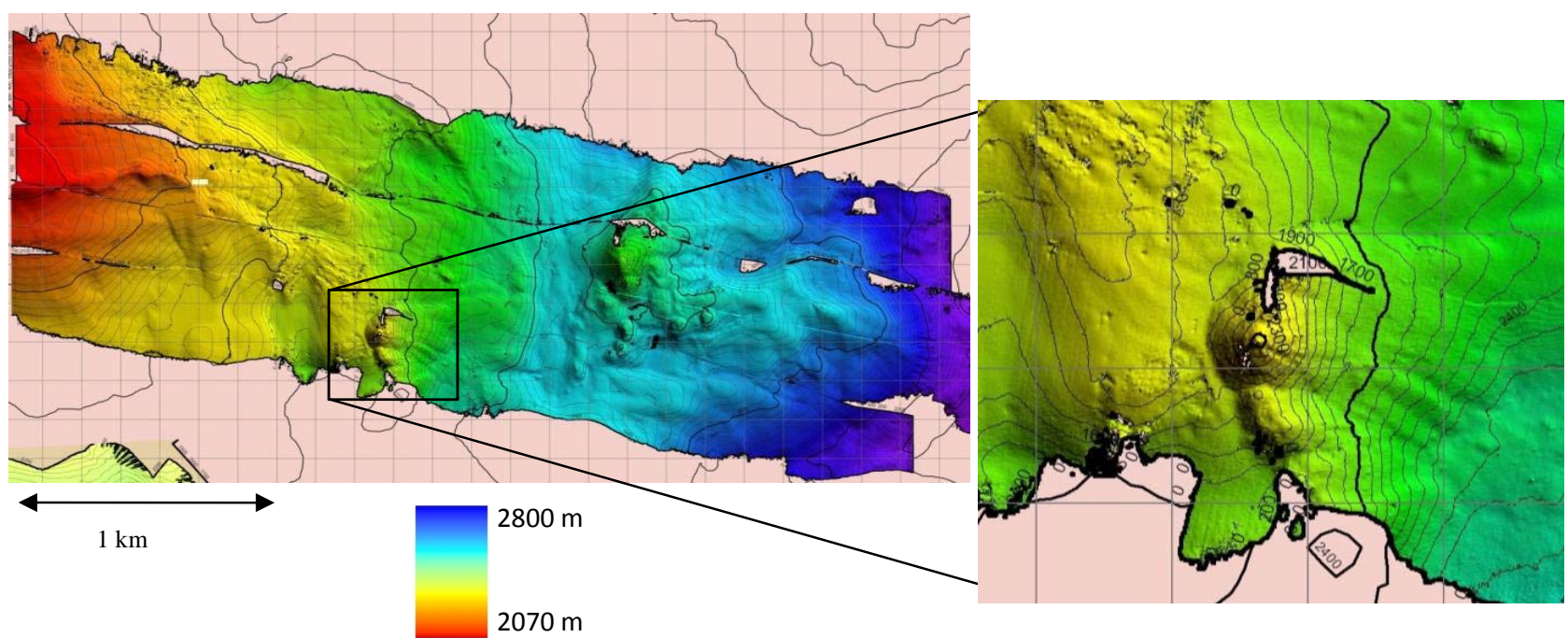

Figure 8. High resolution EM2000 multibeam of the hydrothermal vent site near the summit of Mount Dent (Mission 33, Area 'B'). The vents were later confirmed using the HyBIS video grab system, on the northern flank of the mount in the inset image.

The final mission over Mount Dent was intended to fill in gaps in the high resolution multibeam bathymetry (Fig. 9). This, a mission of three composite survey boxes, revealed another potential vent site, with a small signal detected $2 \mathrm{~km}$ to the south west of the signal already confirmed to be due to a hydrothermal vent. There was not time to investigate this further on the cruise, and this will likely be a subject for further investigation by the Remotely Operated Vehicle, ISIS, on the second UK cruise to the area in 2012. During this mission, there as also an opportunity to carry out basic engineering tests of a long range camera system based upon a Prosilica mono digital camera, using the Sony Exview ICX285 sensor. Encouraging and useful engineering results were obtained, with useable seabed images obtained at $35 \mathrm{~m}$ altitude.

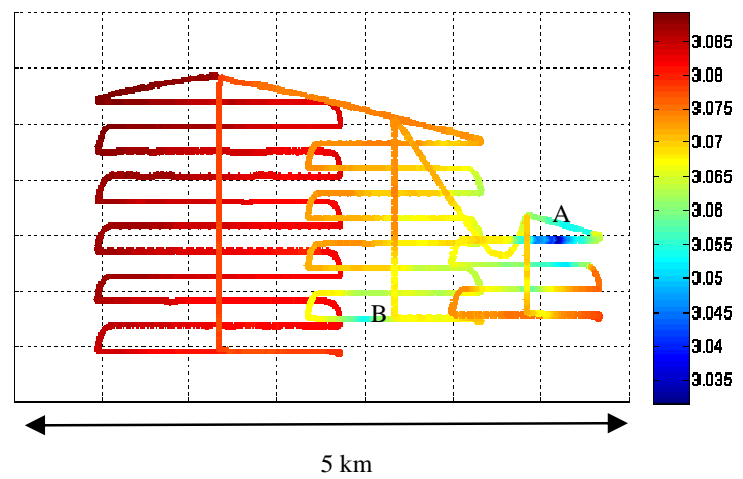

Figure 9. The final sensor survey mission over Mnt. Dent. The survey box is $4000 \mathrm{~m} \mathrm{~N} / \mathrm{S}, 5000 \mathrm{~m} \mathrm{E} / \mathrm{W}$. comprising three successive lawnmower surveys. There is evidence for two vent sites, ' $A$ and $B$ '. ' $A$ ' has been positively identified as a hydrothermal vent site.

\section{C) Plume Detection Efficiency}

If AUVs are to be used for wide area searched for hydrothermal vent systems, it is important to try and optimise the search strategy. Whereas 'intelligent' search techniques may well be useful for pin-pointing the position of a vent which has already been detected, the critical initial problem is in defining the line spacing and altitude settings in order to detect anything at all. The data collected from this cruise, although limited (vent signals were detected on 6 missions from two vent sites), gives us an indication of the minimum line spacing and flight altitude which would be needed to detect a signal.

The results for this cruise ( Figure 10) are rather surprising for two reasons:

1) At a $40 \mathrm{~m}$ altitude a source is detected over a range of $500 \mathrm{~m}$; at $60 \mathrm{~m}$ between $300 \mathrm{~m}$ and $650 \mathrm{~m}$. Contrast this with the theoretical expectation of a 60 degrees total cone angle for a turbulent buoyant plume, given in [10], for which the cone width would be expected to be $46 \mathrm{~m}$, and $69 \mathrm{~m}$ respectively. A steady current obviously helps, as it smears out the plume in one direction, making it easier to intercept, however, the wide across current spread of the plume in mission 28 and 29 is not so easily explained.

2) Further, contrary to our expectations, increasing the flight altitude from about $50 \mathrm{~m}$ to $100 \mathrm{~m}$ does not appear to increase the chances of intercepting a plume signal (at a fixed line spacing).

We will not speculate on the possible explanation for these apparent anomalies, but it is good news for an AUV such as Autosub6000 when used in fully autonomous mode, unaided with external positioning systems, (and I stress again the limited data on which this is based), which has an effective 
altitude limit (200 m), beyond which accurate navigation is not possible.

Based solely on the data gather for this cruise, then with an AUV flying at $100 \mathrm{~m}$, then we should expect a good probability of detecting all the sources, with a line spacing of about $200 \mathrm{~m}$, orthogonal to the current. Fortuitously, this is also an ideal height and line spacing for gathering high resolution multibeam data.

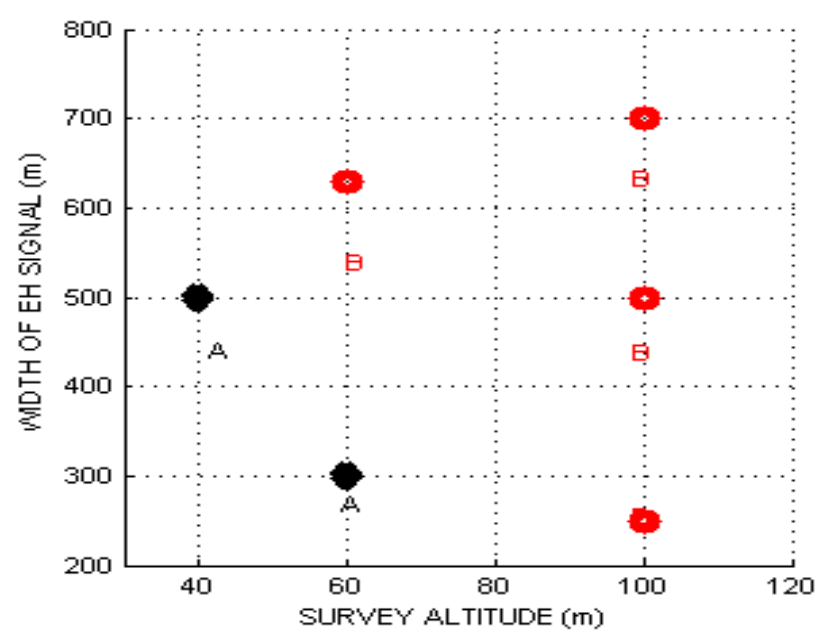

Figure 10. The width of the detected EH signal vs the AUV survey altitude for the 6 plume detecting for the two sites: A and B. With this (limited) data, there is no evidence for a correlation between the survey altitude and the width of the detected plume using a redox potential $(\mathrm{EH})$ sensor

\section{Conclusions}

This was the first science funded cruise for the Autosub6000 AUV. The primary objective for the AUV was quite simply to search for and pin point the position of hydrothermal vent sites in the MCR , so that they could be imaged and sampled at a later time, either on the same cruise (by the HyBIS camera grab system), or on the $2^{\text {nd }}$ leg (by the ISIS ROV). In this goal, the AUV was very successful. Nine missions successfully were completed, 3 at over $5000 \mathrm{~m}$ water depth, the deepest at 5220 $\mathrm{m}$. The AUV completed over 200 hours of mission time, with $690 \mathrm{~km}$ of survey line, and $100 \mathrm{~km}^{2}$ surveyed. Two vents sites were found, and these were filmed shortly afterward by the HyBIS video grab system. Other suspicious signals were located, and these will be further investigated in future cruises. The AUV was able to cope with extreme relief including 45 degree slopes and $70 \mathrm{~m}$ cliffs, and for this the correct operation of the recently developed collision avoidance system was essential. High resolution multibeam surveys were executed for all the areas of interest, and an experimental three axis magnetometry and high altitude camera system both gave promising results.

Not everything worked perfectly. The navigation of the first mission in particular, was seriously in error. However the pragmatic work around (post-mission manual matching of multibeam bathymetry tracks), mirrors our intended approach to vastly improve the future autonomous navigation performance for area surveys. We already gather the data for developing this for each area survey mission. For each one of the AUV area surveys, following the initial positioning at the seabed, the AUV runs a multibeam survey track at right angles to through the mid point of the survey lines. This relatively well navigated track of high resolution multibeam, can then later used as a reference as the AUV later crosses the track. This auto - TERCOM (terrain contour mapping), is giving promising results with offline processing. We intend to apply this to online, during a mission, such that the near disaster of the mission 29 cannot reoccur.

\section{Acknowledgements}

The authors would like to thank the Master, the crew and all participants of James Cook Cruise 044 to the Mid Cayman Rise. We wish also to thank Dr. Chris German for making the $\mathrm{R} / \mathrm{V}$ Cape Hatteras data available to us, greatly assisting our vent searches.

\section{References}

1. Yoerger, D., et al., "Techniques for Deep Sea Near Bottom Survey Using an Autonomous Underwater Vehicle", in Robotics Research. p. 416-429. 2007.

2. German, C.R., et al., "Hydrothermal activity on the southern MidAtlantic Ridge: Tectonically- and volcanically-controlled venting at 4 5S", Earth and Planetary Science Letters, 273(3-4): p. 332-344, 2008.

3. A. Bowen, D. R. Yoerger, C. Taylor, R. McCabe, J. Howland, D. Gomez-Ibanez, J.C. Kinsey, M. Heintz, G. McDonald, D. B. Peters, B. Fletcher, C. Young, J. Buescher, L. L. Whitcomb, S. C. Martin, S. E. Webster, M. V. Jakuba, "The Nereus Hybrid Underwater Robotic Vehicle for Global Ocean Science Operations to 11,000m Depth", Proc.of IEEE/MTS Oceans 2008, Quebec, September 17, 2008.

4. Reves-Sohn, R. A.; H. Singh, S. Humphris, T. Shank, T, M. Jakuba, C. Kunz, C. Murphy, C. Willis, "The Arctic Gakkel Vents (AGAVE) Expedition: Technology Development and the Search for Deep-Sea Hydrothermal Vent Fields Under the Arctic Ice Cap", Proc. American Geophysical Union, Fall Meeting 2007, abstract \#P52A-02 . 2007. AGUFM.P52A..02R.

5. Ura, T., "Dive of AUV r2D4 to The Great Dodo Lava Plain in the Rift Valley of the Central Indian Mid-Ocean Ridge System", Proc. Symposium on Underwater Technology, Tokyo . 2007

6. Huvenne, V. A. I., McPhail, S.D., Wynn, R.B., Furlong, M. and Stevenson, P. Mapping Giant Scours in the Deep Ocean", EOS: Transactions American Geophysical Union, 90; 274-275, 2009.

7. McPhail, S., M Furlong, M. Pebody, "Low Altitude Terrain Following and Collision Avoidance in a Flight Class Autonomous Underwater Vehicle", Proc. of the Institution of Mechanical Engineers, Part M, Journal of Engineering for the Maritime Environment, In Press. 2010.

8. McPhail, S. D., et al., "Exploring beneath the PIG Ice Shelf with the Autosub3 AUV", in Proc. Oceans 09, Balancing Technology with Future Needs, IEEE: Bremen. 2009

9. McPhail, S. D. and Pebody, M. "Range-only positioning of a deepdiving Autonomous Underwater Vehicle from a surface ship2, IEEE Journal of Oceanic Engineering, 34, (4), 669-677, 2009

10. Turner, J. S. " Buoyancy Effects in Fluids", Cambridge University Press, New York, 1973. 